\title{
Obstructive sleep apnea and non-alcoholic fatty liver disease: is the liver another target?
}

\author{
Aibek E. Mirrakhimov ${ }^{1}$ and Vsevolod Y. Polotsky ${ }^{2 *}$ \\ 1 I.K. Akhunbaev Kyrgyz State Medical Academy, Bishkek, Kyrgyzstan \\ 2 Division of Pulmonary and Critical Care Medicine, Johns Hopkins University School of Medicine, Baltimore, MD, USA
}

\section{Edited by:}

Pierre-Charles Neuzeret, Lyon Neuroscience Research Center, France

\section{Reviewed by:}

Luciano Drager, University of Sao Paulo Medical School, Brazil

Jean-Pierre Zarski, CHU de Grenoble,

France

\section{*Correspondence:}

Vsevolod Y. Polotsky, Division of Pulmonary and Critical Care

Medicine, Johns Hopkins Asthma and Allergy Center, Johns Hopkins

University School of Medicine, 5501 Hopkins Bayview Circle, Room 4B 65,

Baltimore, MD 21224, USA.

e-mail:vpolots1@jhmi.edu

\begin{abstract}
Obstructive sleep apnea (OSA) is recurrent obstruction of the upper airway during sleep leading to intermittent hypoxia $(\mathrm{IH})$. OSA has been associated with all components of the metabolic syndrome as well as with non-alcoholic fatty liver disease (NAFLD). NAFLD is a common condition ranging in severity from uncomplicated hepatic steatosis to steatohepatitis (NASH), liver fibrosis, and cirrhosis. The gold standard for the diagnosis and staging of NAFLD is liver biopsy. Obesity and insulin resistance lead to liver steatosis, but the causes of the progression to NASH are not known. Emerging evidence suggests that OSA may play a role in the progression of hepatic steatosis and the development of NASH. Several cross-sectional studies showed that the severity of $\mathrm{IH}$ in patients with OSA predicted the severity of NAFLD on liver biopsy. However, neither prospective nor interventional studies with continuous positive airway pressure treatment have been performed. Studies in a mouse model showed that $\mathrm{IH}$ causes triglyceride accumulation in the liver and liver injury as well as hepatic inflammation. The mouse model provided insight in the pathogenesis of liver injury showing that (1) $\mathrm{IH}$ accelerates the progression of hepatic steatosis by inducing adipose tissue lipolysis and increasing free fatty acids (FFA) flux into the liver; (2) IH upregulates lipid biosynthetic pathways in the liver; (3) IH induces oxidative stress in the liver; (4) IH up-regulates hypoxia inducible factor 1 alpha and possibly HIF-2 alpha, which may increase hepatic steatosis and induce liver inflammation and fibrosis. However, the role of FFA and different transcription factors in the pathogenesis of IH-induced NAFLD is yet to be established. Thus, multiple lines of evidence suggest that IH of OSA may contribute to the progression of NAFLD but definitive clinical studies and experiments in the mouse model have yet to be done.
\end{abstract}

Keywords: sleep apnea, intermittent hypoxia, non-alcoholic fatty liver disease, non-alcoholic steatohepatitis

\section{INTRODUCTION}

Obstructive sleep apnea (OSA) is a common disorder that affects $4-24 \%$ of men and 2-9\% of women in the United States (Young et al., 1993), but the prevalence of OSA exceeds 30-50\% in obese individuals Punjabi et al. (2002), Vgontzas et al. (2000), Young et al. (1993), Tufik et al. (2010), Young et al. (2002). OSA is characterized by recurrent upper airway collapse during sleep resulting in fragmentation of sleep and recurrent oxyhemoglobin desaturations termed chronic intermittent hypoxia ( $\mathrm{IH}$; Gastaut et al., 1966). OSA markedly increases mortality and morbidity due to the increased cardiovascular risk (Gami et al., 2005; Yaggi et al., 2005; Marshall et al., 2008; Young et al., 2008; Punjabi et al., 2009). The cardiovascular risk of OSA has been attributed to metabolic dysfunction (Jun and Polotsky, 2009; Lavie and Polotsky, 2009; Drager et al., 2010a). OSA is associated with all manifestations of the metabolic syndrome, including visceral obesity, hypertension, dyslipidemia, and insulin resistance (Levy et al., 2009; Drager et al., 2010b; Sharma et al., 2011; Bonsignore et al., 2012). Recent clinical data suggests that metabolic dysfunction of OSA is associated with nocturnal $\mathrm{IH}$, independent of obesity (Drager et al., 2010b; Bonsignore et al., 2012). Experiments in a mouse model of
IH mimicking oxyhemoglobin desaturations in patients with OSA showed that $\mathrm{IH}$ induces insulin resistance, glucose intolerance, and dyslipidemia in the absence of obesity (Li et al., 2005b, 2006, 2007; Iiyori et al., 2007; Savransky et al., 2007b), but the effects of $\mathrm{IH}$ are particularly severe in the presence of obesity (Polotsky et al., 2003; Drager et al., 2011). Recent studies in healthy human volunteers have also shown that $\mathrm{IH}$ induces insulin resistance, independent of obesity (Louis and Punjabi, 2009). Insulin resistance and dyslipidemia induced by OSA can be reversed by continuous positive airway pressure (CPAP; Robinson et al., 2004; Sharma et al., 2011). OSA is associated with another manifestation of metabolic dysfunction, non-alcoholic fatty liver (NAFLD; Tanne et al., 2005; Jouet et al., 2007; Kallwitz et al., 2007; Polotsky et al., 2009). Animal and human data indicate that IH of OSA may contribute to the progression of NAFLD, a common condition with the prevalence between 17 and $33 \%$ and the major risk factors being obesity and insulin resistance (Hilden et al., 1977; Nomura et al., 1988; Bellentani et al., 2000; Browning and Horton, 2004; Browning et al., 2004; Clark, 2006; McCullough, 2006). In this article, we will review available clinical evidence on the relationships between OSA and liver disease and examine putative 
mechanisms linking sleep disordered breathing and nocturnal $\mathrm{IH}$ with NAFLD. We will begin with a brief overview of NAFLD.

\section{NAFLD: CLINICAL OVERVIEW}

Non-alcoholic fatty liver disease includes a spectrum of the disease severity, ranging from steatosis without inflammation to nonalcoholic steatohepatitis (NASH) and liver cirrhosis (Day and James, 1998; Browning and Horton, 2004; Diehl, 2005). NASH is a progressive fibrotic disease, in which cirrhosis and liver-related death occur in up to 20 and $12 \%$ patients, respectively (McCullough, 2004). Approximately $10-30 \%$ patients with hepatic steatosis have histological features of NASH (McCullough, 2006; Tilg and Moschen, 2010). NASH is the most common cause of cryptogenic liver cirrhosis in the U.S. (Caldwell et al., 1999; Clark and Diehl, 2003). NASH has also been implicated in causality of at least 7\% of cases of hepatocellular carcinoma (Bugianesi et al., 2002). Multiple treatment options were considered for NASH, but, with a possible exception of a moderate benefit from vitamin E, effective therapy is still lacking (Kashi et al., 2008; Torres and Harrison, 2008; Vuppalanchi and Chalasani, 2009; Sanyal et al., 2010).

To this date, liver biopsy remains the gold standard to diagnose and stage NAFLD (Clark and Diehl, 2003; Vuppalanchi and Chalasani, 2009). The Pathology Committee of the NASH Clinical Research Network developed a histological scoring system that determines the severity of NAFLD based on a NAFLD activity score (NAS; Kleiner et al., 2005), which is now being uniformly used. This scoring system assesses a degree of steatosis, lobular inflammation, hepatocellular ballooning, and fibrosis. NAS is a sum of steatosis, lobular inflammation, and hepatocellular ballooning scores. Fibrosis was not included as a component of NAS, because it is less reversible and does not reflect the acuteness of the inflammatory process. NAS $\geq 5$ is considered NASH, whereas NAS $<3$ excludes NASH (Kleiner et al., 2005).

Liver biopsy is an invasive procedure, therefore non-invasive biomarkers of NAFLD is a desirable alternative. Serum alanine and aspartate aminotransferases (ALT and AST) indicate liver injury, but are neither sensitive nor specific to diagnose NAFLD and characterize its severity (Clark and Diehl, 2003; Browning et al., 2004). Serum alkaline phosphatase (AP) and gamma glutamyl transpeptidase (GGT) may indicate intrahepatic cholestasis, but cannot be used to assess liver injury. Serum ferritin has been suggested as a biomarker of NAFLD (Licata et al., 2009; Manousou et al., 2011; Kim et al., 2012; Kowdley et al., 2012). Serrum ferritin is independently associated with advanced hepatic fibrosis (odds ratio, OR, 1.66) and increased NAS (OR, 1.99; Kowdley et al., 2012). The NASH Clinical Research Network currently recommends serum ferritin to identify NAFLD patients at risk for NASH and advanced fibrosis However, the sensitivity and specificity of ferritin for the diagnosis of NASH are relatively low (Kowdley et al., 2012).

Over the last decade several biochemical panels were developed and tested as surrogate markers of NAFLD. FibroTest includes $\alpha 2-$ macroglobulin, apolipoprotein A1, haptoglobin, total bilirubin, and GGT adjusted for age and gender. ActiTest includes same five components and ALT. SteatoTest and NashTest include the same components as ActiTest plus serum glucose, triglycerides, and cholesterol adjusted for age, gender, and BMI (Poynard et al., 2012). The value of these biochemical panels has been systematically reviewed in a recent meta-analysis in severely obese individuals (Poynard et al., 2012). FibroTest has very low sensitivity and negative predictive value for the diagnosis of liver fibrosis (13.4 and $51.5 \%$, respectively), but high specificity and positive predictive value ( 97.5 and $85 \%$, respectively). Depending on the value cut-off, SteatoTest and NashTest had either low sensitivity and relatively high specificity or vice versa for respective diagnoses of hepatic steatosis and NASH (Poynard et al., 2012). Other biomarker panels such as FibroSpect II (hyaluronic acid, tissue inhibitor of matrix metalloproteinase I, $\alpha 2$-macroglobulin), $\mathrm{N}$-terminal propeptide of type III collagen, and others have not been validated in NAFLD (Baranova et al., 2011). Overall, biochemical serum testing may identify patients at risk of NAFLD and NASH but does not allow reliably stage the disease.

Recent progress in imaging technology, ultrasound, computer tomography, magnetic resonance imaging (MRI), and magnetic resonance spectroscopy (MRS) allow reliably diagnose and quantify hepatic steatosis (Springer et al., 2010; Hernaez et al., 2011; Patel et al., 2011). A novel ultrasound technology FibroScan has recently been developed (Friedrich-Rust et al., 2010; Myers et al., 2012a,b). The FibroScan (Echosens, Paris, France) allows simultaneous assessment of hepatic steatosis and fibrosis. The Controlled Attenuation Parameter (CAP) measures the degree of ultrasound attenuation by hepatic fat simultaneously with liver stiffness measurements. CAP values significantly correlated with the degree of steatosis on liver biopsy ( $r=0.47-0.51$; Myers et al., 2012a). Compared to liver histology, the diagnostic accuracy of ultrasound transient elastography in significant liver fibrosis is 0.80 for the $\mathrm{M}$ probe and 0.82 for the XL probe and in liver cirrhosis is 0.91 for the M probe and 0.95 for the XL probe (Friedrich-Rust et al., 2010). The diagnostic performance of the XL probe was found to be superior to the $\mathrm{M}$ probe for liver stiffness measurements in obese patients (Friedrich-Rust et al., 2010). Magnetic resonancebased elastography is another promising technique to detect liver fibrosis (Bonekamp et al., 2009). Thus, non-invasive novel imaging techniques can detect hepatic steatosis and liver fibrosis with a reasonable accuracy, but do not allow the assessment of hepatic inflammation.

\section{NAFLD: PATHOGENESIS}

Day and James (1998) proposed a "two-hit" model to explain the progression of NAFLD. The "first hit" involves the accumulation of triglyceride in hepatocytes, and has been specifically attributed to insulin resistance and obesity. Obesity and insulin resistance are characterized by increased adipocyte mass and increased hormone-sensitive lipase activity, which leads to up-regulation of lipolysis and increased uptake of free fatty acids (FFA) by the liver (Browning and Horton, 2004). In turn, increased FFA uptake induces triglyceride biosynthesis and hepatic steatosis. In addition, high levels of insulin in obese individuals may up-regulate hepatic lipid biosynthesis de novo by activating a master-regulator of lipid biosynthesis, a transcription factor sterol regulatory element binding protein-1c (SREBP-1c; Foretz et al., 1999; Shimomura et al., 1999b) and a SREBP-1-regulated enzymes of triglyceride biosynthesis stearoyl coenzyme A desaturase 1 (SCD-1; Cohen et al., 2002; Biddinger et al., 2005) and diacylglycerol acyltransferases (DGAT). Persistent hyperglycemia in patients with diabetes 
may activate another lipogenic transcription factor, carbohydrate response element binding protein (ChREBP; Iizuka et al., 2004; Dentin et al., 2006; Ma et al., 2006; Postic et al., 2007; Davies et al., 2008). Over-expression of SREBP-1c has been shown to lead to fatty liver in mouse models of insulin resistance and obesity (Shimomura et al., 1998, 1999a), and can account for the development of hepatic steatosis in human subjects. In turn, hepatic fat accumulation increases insulin resistance stimulating gluconeogenesis and activating protein kinase $\mathrm{C}-\varepsilon$ and janus kinase 1 , which interfere with tyrosine phosphorylation of insulin receptor substrates 1 and 2 and impair the ability of insulin to activate glycogen synthase (Samuel et al., 2004; Savage et al., 2007).

When hepatic steatosis progresses to NASH, hepatic lobules become infiltrated with a mixed population of inflammatory cells. Inflammation is followed or accompanied by hepatocyte ballooning and necrosis, appearance of Mallory bodies, and, finally, perisinusoidal fibrosis, or cirrhosis (Ludwig et al., 1997; CarmielHaggai et al., 2005). The progression of hepatic steatosis to NASH has been attributed to a "second hit" that leads to the development of liver inflammation and fibrosis (Day and James, 1998). Obesity, age over 45 years, diabetes, hypertriglyceridemia, and hypertension have been identified as risk factors for the progression of NAFLD (Angulo et al., 1999; Dixon et al., 2001; Bugianesi et al., 2002). The progression of NAFLD to NASH was linked to oxidative stress and lipid peroxidation in the liver, leading to inflammation (Robertson et al., 2001; George et al., 2003; Bergamini et al., 2004; Browning and Horton, 2004; Laurent et al., 2004; Carmiel-Haggai et al., 2005; Oliveira et al., 2005; Seki et al., 2005; McCullough, 2006).

"A two-hit" model of NAFLD progression has been recently revised. Simple steatosis, which never progresses in $70-90 \%$ of NAFLD patients, might be a separate entity from relentlessly progressing NASH. Inhibition of DGAT-1 or SCD-1 improves liver steatosis but worsens liver damage suggesting that accumulation of triglycerides in the liver may protect against NASH (Yamaguchi et al., 2007, 2008; Li et al., 2009; Tilg and Moschen, 2010). NASH could be a result of multiple hits to the liver with major contribution of pathologically enhanced lipolysis of visceral and subcutaneous adipose tissue and ensuing hepatic lipotoxicity (Neuschwander-Tetri, 2010). Other hits include pro-inflammatory cytokines and adipokines derived from adipose tissues such as leptin, IL-6, TNF- $\alpha$ as well as gut-derived factors and endoplasmic reticulum stress (Tilg and Moschen, 2010). Recent clinical evidence suggests that OSA may lead to NAFLD progression, whereas experimental literature showed that $\mathrm{IH}$ induces liver injury and steatohepatitis.

\section{NAFLD AND OSA: CLINICAL EVIDENCE}

Several cross-sectional studies examined levels of liver enzymes in serum of patients with OSA (Table 1). Chin et al. (2003) were first to report abnormally elevated morning AST levels in 14 out of 40 studied OSA patients (35\%). Increased liver enzymes correlated with insulin resistance measured by the homeostasis model assessment method (HOMA). Norman et al. (2008) demonstrated in 109 patients with OSA that ALT and AST levels directly correlated with the severity of nocturnal hypoxia, but not with the apnea-hypopnea index (AHI) or BMI. Increased ALT, AST, and AP in adult patients with moderate and severe OSA have also been reported by Shpirer et al. (2010). Gude et al. (2009) studied a randomly selected a population sample of 220 individuals and found that serum GGT levels directly correlated with a degree of nocturnal hypoxemia (Tables 1 and 2). Unfortunately, all of the above studies lacked a control group.

Several cross-sectional studies compared OSA patients to control subjects. Kheirandish-Gozal et al. (2008) reported significantly higher serum ALT levels in children with OSA compared to children without OSA. In bariatric population, Kallwitz et al. (2007) and Jouet et al. (2007) reported a higher prevalence of elevated ALT levels in patients with OSA compared to those without OSA. In the sleep clinic population, the presence of severe OSA (AHI > 50) was an independent predictor of elevated liver enzymes (Tanne et al., 2005). Notably, several studies in the bariatric and sleep clinic populations found no relationship between liver enzymes and the presence or severity of OSA (Polotsky et al., 2009; Aron-Wisnewsky et al., 2012). Liver enzymes remained within normal limits, despite significant changes on histopathology. One study reported a direct correlation between a serum marker of liver fibrosis, type III procollagen, and triglyceride and fasting plasma glucose, but not ALT or AST (Tatsumi and Saibara, 2005). The effect of CPAP on ALT and AST level was assessed a non-randomized uncontrolled clinical trial by Chin et al. (2003), who reported that one night of CPAP significantly decreased morning AST levels and abolished morning increases in AST and ALT. However, the only randomized placebo controlled study failed to find any effect of therapeutic CPAP treatment for 4 weeks on liver enzymes compared to sham CPAP (Kohler et al., 2009). Overall, evidence that OSA has an independent effect on liver enzyme levels remains inconclusive and may pertain only to severe OSA with marked nocturnal oxyhemoglobin desaturations. Given that elevated liver enzymes are neither sensitive nor specific markers of NAFLD and NASH (Clark and Diehl, 2003; Browning et al., 2004), studies focusing on liver enzymes could not elucidate relationships between OSA and NAFLD. Other serum biomarkers of NAFLD (NAFLD: Clinical Overview) have not been studied in patients with OSA.

\section{OSA AND LIVER IMAGING STUDIES}

To our knowledge, there have been only four liver imaging studies in patients with OSA, three of which utilized computer tomography (CT) to assess the degree of hepatic steatosis (Tatsumi and Saibara, 2005; Shpirer et al., 2010; Hoyos et al., 2012) and one study used MRI/MRS. Tatsumi and Saibara (2005) measured the amount of visceral and liver fat in patients with OSA (AHI $>5 / \mathrm{h}$ ) compared to non-OSA subjects and found that the presence of OSA was associated with increased visceral adiposity, but not with the degree of hepatic steatosis (Table 1). Shpirer et al. (2010) retrospectively analyzed liver CT in 47 patients with OSA and found an association between hepatic steatosis and the severity of OSA. However, patients with severe OSA and hepatic steatosis on CT had a higher BMI and, therefore, the results of the study were confounded by obesity. The effect of CPAP treatment for 3 years was examined in 11 patients. CPAP therapy was associated with a decrease in hepatic steatosis in six compliant patients, despite unchanged BMI, but not in five non-compliant patients. Hoyos et al. (2012) recruited patients with moderate-severe OSA and 
Table 1 | Studies that measured liver enzymes and/or imaged liver in patients with OSA.

\begin{tabular}{|c|c|c|c|c|}
\hline Study & $\begin{array}{l}\text { Sample size } \\
\text { (OSA/controls) }\end{array}$ & Type of the study & Outcome & Findings \\
\hline Chin et al. (2003) & Adults $40 / 0$ & $\begin{array}{l}\text { Cross-sectional followed by } \\
\text { a non-randomized trial of } \\
\text { CPAP for one night }\end{array}$ & ALT, AST, TG, insulin, IR & $\begin{array}{l}\uparrow A L T \text { and } A S T \text { in the morning } \\
\text { attenuated by CPAP. No change in } \\
\text { IR, TG, and insulin }\end{array}$ \\
\hline $\begin{array}{l}\text { Norman et al. } \\
\text { (2008) }\end{array}$ & Adults 109/0 & Cross-sectional study & $\begin{array}{l}\text { ALT, AST, glucose, TC, TG, } \\
\text { HDL, LDL }\end{array}$ & $\begin{array}{l}\text { Minimal nocturnal SpO2 inversely } \\
\text { correlated and \% T90 directly } \\
\text { correlated with ALT and AST. No } \\
\text { effect of AHI or other metabolic } \\
\text { biomarkers }\end{array}$ \\
\hline $\begin{array}{l}\text { Kheirandish-Gozal } \\
\text { et al. (2008) }\end{array}$ & $\begin{array}{l}\text { Children } 343 \text { patients; } \\
175 \text { non-OSA habitual } \\
\text { snorers }\end{array}$ & Cross-sectional study & $\begin{array}{l}\text { ALT, AST, glucose, insulin, } \\
T G, H D L, L D L\end{array}$ & $\begin{array}{l}\uparrow A L T \text {, insulin, } T C, L D L \text {, and } \downarrow H D L \text { in } \\
\text { patients with OSA, } \uparrow \text { prevalence of } \\
\text { OSA in obese patients with } \\
\text { elevated ALT }\end{array}$ \\
\hline Gude et al. (2009) & $\begin{array}{l}\text { Adults } 220 \text { (only } 70 \text { had } \\
\text { PSG) }\end{array}$ & $\begin{array}{l}\text { Cross-sectional population } \\
\text { study }\end{array}$ & $\begin{array}{l}\text { GGT, glucose, TG, IL-6, } \\
\text { TNF- } \alpha\end{array}$ & $\begin{array}{l}\text { GGT inversely correlated with mean } \\
\text { and minimal SpO2 and directly } \\
\text { correlated with } \% \text { T90, independent } \\
\text { of all other variables. No effect of } \\
\text { AHI }\end{array}$ \\
\hline $\begin{array}{l}\text { Tatsumi and } \\
\text { Saibara (2005) }\end{array}$ & $83 / 41$ & Cross-sectional study & $\begin{array}{l}\text { Liver/spleen ratio by } \\
\text { computer tomography, } \\
\text { serum P-III-P }\end{array}$ & $\begin{array}{l}\text { P-III-P levels inversely with average } \\
\text { nocturnal } \mathrm{SpO}_{2} \text {. No effect of OSA } \\
\text { on the liver/spleen ratio }\end{array}$ \\
\hline $\begin{array}{l}\text { Shpirer et al. } \\
\text { (2010) }\end{array}$ & $47 / 0$ CPAP in $16 / 0$ & $\begin{array}{l}\text { Cross-sectional study and } \\
\text { retrospective analysis of } \\
\text { CPAP treatment for } 3 \text { years }\end{array}$ & $\begin{array}{l}\text { ALT, AST, AP, liver } \\
\text { attenuation index by } \\
\text { computer tomography }\end{array}$ & $\begin{array}{l}\uparrow A L T \text {, AST, AP in moderate-severe } \\
\text { OSA compared to mild OSA. } \downarrow \text { liver } \\
\text { attenuation in CPAP-compliant } \\
\text { patients ( } n=6 \text { ) compared to } \\
\text { non-compliant }\end{array}$ \\
\hline
\end{tabular}

$A L T$, alanine aminotransferase; AST, aspartate aminotransferase; AP, alkaline phosphatase; GGT, gamma glutamyl transpeptidase; IR, insulin resistance; MRI/MRS, magnetic resonance imaging \& magnetic resonance spectroscopy; $\mathrm{SpO}_{2}$, oxyhemoglobin saturation; P-III-P, type III procollagen; \% T90, sleep time with SaO $<90 \%$; $T C$, total cholesterol; $T G$, triglycerides.

performed a randomized double-blinded sham controlled trial of CPAP for 12 weeks followed by real CPAP treatment for 12 weeks in all patients. Visceral and liver fat were measured by CT; insulin sensitivity was assessed based on fasting blood glucose and insulin; serum leptin and adiponectin were measured. There was no effect of CPAP on liver steatosis or any metabolic parameters at 12 weeks. Insulin sensitivity improved at 24 weeks, while liver fat and all other biomarkers remained unchanged. Sivam et al. (2012) performed a randomized double-blinded sham controlled trial of CPAP for 8 weeks and reported no effect of CPAP on liver fat or liver enzyme with exception of a mild decline in AP. Imaging studies have not been used to assess liver fibrosis in OSA. Thus, literature on liver imaging in OSA is fragmentary and inconclusive.

\section{OSA AND LIVER PATHOLOGY}

The gold standard of NAFLD diagnosis, staging, and prognosis is liver biopsy. The first case report of severe NASH with intralobular and periportal inflammation, hepatocyte ballooning, and pericellular fibrosis in a patient with obesity hypoventilation syndrome was published in 2002 (Saibara et al., 2002). Since that time a number of studies examining relationships between OSA and findings in liver biopsy have been conducted (Table 2). All of these studies are cross-sectional, because it is not feasible to obtain liver biopsy repeatedly due to ethical considerations. Studies, in which polysomnography (PSG) has not been performed could not be used for the reliable analysis of the OSA-NAFLD association and will not be further discussed. In the first PSG based study, Tanne 
Table 2 | Cross-sectional studies that examined liver biopsies in patients with OSA.

\begin{tabular}{|c|c|c|c|}
\hline Study & Sample size & Outcome & Findings \\
\hline Singh et al. (2005) & $\begin{array}{l}190 \text { NAFLD patients (only steatosis on } \\
\text { biopsy or CT/US in 116, biochemical NASH by } \\
\uparrow A L T \text { or AST to } 1.5 \text { of normal in } 74 \text { ), including } \\
50 \text { confirmed by liver biopsy ( } 18 \text { steatosis, } 32 \\
\text { NASH) }\end{array}$ & $\begin{array}{l}\text { Modified Berlin Sleep } \\
\text { Apnea Questionnaire for } \\
\text { OSA. No PSG }\end{array}$ & $\begin{array}{l}\text { Eighty-seven ( } 46 \% \text { ) patients met criteria for OSA. } \\
\text { The prevalence was similar in both biochemically } \\
\text { and histologically defined steatosis and NASH. }\end{array}$ \\
\hline $\begin{array}{l}\text { Kallwitz et al. } \\
(2007)\end{array}$ & $\begin{array}{l}\text { Records from } 101 \text { bariatric patients reviewed } \\
\text { retrospectively. } 85 \text { patients had liver } \\
\text { enzymes, sleep studies, and liver biopsy. } \\
51 \% \text { had OSA identified by an } A H I \geq 15 / h\end{array}$ & $\begin{array}{l}\text { ALT, AST. Liver steatosis, } \\
\text { inflammation, and } \\
\text { fibrosis }\end{array}$ & $\begin{array}{l}\uparrow A L T \text { in OSA. } \uparrow \text { Prevalence of OSA in patients } \\
\text { with inflammation + fibrosis. No association } \\
\text { between OSA and AST, steatosis, hepatitis, bal- } \\
\text { loon degeneration, or fibrosis }\end{array}$ \\
\hline $\begin{array}{l}\text { Mishra et al. } \\
\text { (2008) }\end{array}$ & $\begin{array}{l}101 \text { bariatric patients, including } 77 \text { patients } \\
\text { with } \mathrm{NASH} \text { and } 24 \text { controls. } 51 \% \text { had OSA } \\
\text { identified by an } \mathrm{AHI}>5 / \mathrm{h}\end{array}$ & PSG & $\begin{array}{l}\downarrow \text { minimal and mean } \mathrm{SpO}_{2} \text {, in patients with } \\
\mathrm{NASH} \text { and liver fibrosis, } \uparrow A \mathrm{HI} \text { in patients with } \\
\mathrm{NASH} \text {. Minimal } \mathrm{SpO}_{2} \text { independently correlated } \\
\text { with histological } \mathrm{NASH}\end{array}$ \\
\hline $\begin{array}{l}\text { Polotsky et al. } \\
\text { (2009) }\end{array}$ & $\begin{array}{l}90 \text { consecutive bariatric patients. Liver } \\
\text { biopsy in } 20 \text { subjects. All patients had PSG }\end{array}$ & $\begin{array}{l}\text { ALT, AST, insulin, glucose. } \\
\text { Liver biopsy }\end{array}$ & $\begin{array}{l}\text { All patients had normal liver enzymes. Mean oxy- } \\
\text { gen desaturation }>4.6 \% \text { was associated with a } \\
1.5 \text { increase in } \mathrm{HOMA} \text {. } \downarrow \mathrm{SpO}_{2} \text { was associated } \\
\text { with lobular inflammation, ballooning, and liver } \\
\text { fibrosis, but not with steatosis }\end{array}$ \\
\hline Daltro et al. (2010) & 40 bariatric patients & $\begin{array}{l}\text { PSG, fasting glucose, } \\
\text { insulin, liver enzyme, liver } \\
\text { biopsy }\end{array}$ & $\begin{array}{l}\uparrow \text { prevalence of OSA ( } 80 \%) \text {, NAFD }(82.5 \%) \text {, and } \\
\text { NASH ( } 80 \%) \text {. OSA was associated with insulin } \\
\text { resistance but not with the severity of NASH }\end{array}$ \\
\hline
\end{tabular}

a-glutathione-S-transferase.

et al. (2005) performed liver biopsy in a small subset of sleep clinic patients with elevated serum liver enzymes and found that subjects with severe OSA defined as the AHI $>50 / \mathrm{h}(n=9)$, exhibited more severe liver steatosis, necrosis, and fibrosis than subjects with the $\mathrm{AHI} \leq 50 / \mathrm{h}(n=9)$. Other studies focused on the bariatric population taking an advantage of the availability of intra-operative liver biopsy. Kallwitz et al. (2007) performed a retrospective review of 101 patients who underwent gastric bypass surgery. Liver biopsy was performed only if the liver had abnormal appearance (enlargement, yellow discoloration, or nodularity). Both PSG and liver biopsy were performed in 85 patients. There was a trend toward a higher prevalence of OSA in patients with inflammation and fibrosis (11/15) compared with those with inflammation alone (22/48). There was no association between OSA and the degree of steatosis, presence of hepatitis, balloon degeneration, or fibrosis on liver biopsy. Similarly, Jouet et al. (2007) also reported the lack of association between OSA and histological markers of NASH. However, relationships between nocturnal hypoxemia and NASH had not been examined. Mishra et al. (2008) studied 101 bariatric patients with biopsy-proven NAFLD, all of whom had full PSG in a sleep laboratory. The lowest desaturation independently correlated with histological NASH. Both mean and lowest oxygen desaturation were independently associated with the presence of liver fibrosis, whereas there was no statistically significant relationships between the AHI and RDI (the respiratory disturbance index defined as a number of apneas, hypopneas, and respiratory effort related arousals per hour) and liver fibrosis. Polotsky et al. (2009) studied 90 consecutive bariatric patients, all of which underwent PSG, and reported the prevalence of OSA (the RDI $>5 / \mathrm{h}$ ) of $81.1 \%$. The analysis of liver biopsies $(n=20)$ showed that lobular inflammation, hepatocyte ballooning, the NAS, and liver fibrosis were associated with severe oxyhemoglobin desaturation (Figure 1), but not the RDI and this association was independent of BMI. Aron-Wisnewsky et al. (2012) performed continuous nocturnal pulse oximetry in 101 bariatric patients who underwent liver needle biopsy intra-operatively. Liver histology was compared in three tertiles of oxygen desaturation index (ODI), <6.7, 6.8-18.5, and $>18.5 / \mathrm{h}$. The BMI was similar in all tertiles varying from 45.7 to 

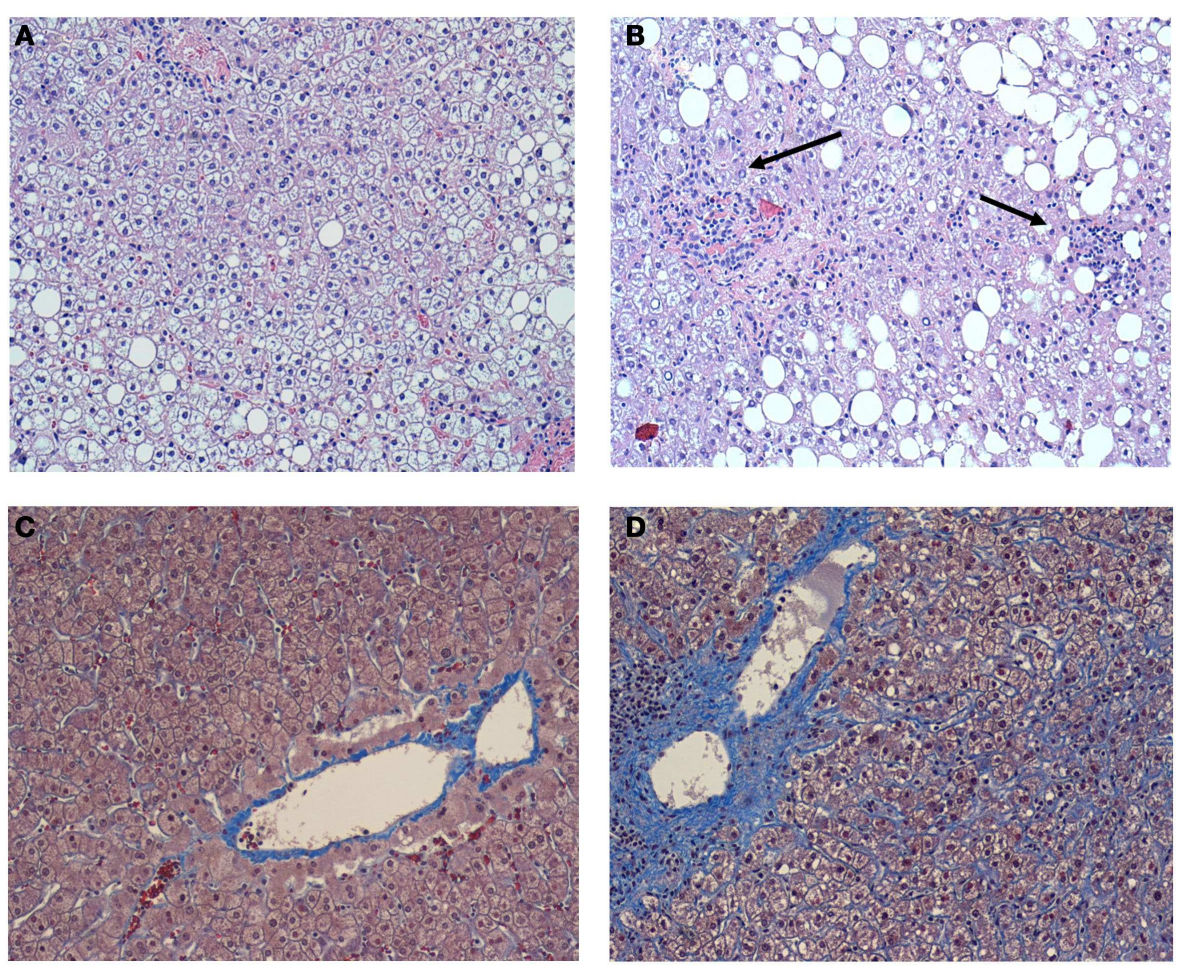

FIGURE 1 | (A) A representative image of the liver without inflammation in the individual without OSA. Hematoxylin-eosin. X 100. Macrovesicular hepatic steatosis is evident, but inflammation is absent; (B) A representative image of the liver in the individual with OSA and severe nocturnal oxyhemoglobin desaturation. Hematoxylin-eosin.X 100. Macrovesicular hepatic steatosis is evident, lobular inflammation is present (arrows); (C) A representative image of the liver without pericellular fibrosis in the individual without OSA. Masson trichrome X 100; (D) A representative image of the liver in the individual with OSA and severe nocturnal oxyhemoglobin desaturation. Masson trichrome $X$ 100. Prominent pericellular perisinusoidal fibrosis is present. Collagen depositions are stained in blue and have chicken-wire appearance. Reproduced with permission from Polotsky et al. (2009).
$48.3 \mathrm{~kg} / \mathrm{m}^{2}$, whereas patients with more severe OSA had higher prevalence of type 2 diabetes, dyslipidemia, and hypertension. There was a significant increase in liver steatosis, ballooning, lobular inflammation, NAS, and liver fibrosis with increased ODI. After the adjustment for type 2 diabetes, inflammation, age, and sex, the ODI remained independently associated with higher NAS and the severity of liver fibrosis. Notably, similarly to Polotsky et al. (2009), ALT and AST values were within the normal range in all patients, regardless of the severity of OSA and NASH. Thus, emerging evidence demonstrates that there is an association between the severity of hypoxic indexes in patients with OSA and the severity of NAFLD diagnosed by liver biopsy. The effect of CPAP treatment on NAFLD pathology has not been examined.

\section{OSA AND HYPOXIC LIVER INJURY}

Although the prevalence of NAFLD in patients with OSA remains unknown, clinical evidence suggests it might be a common phenomenon. In contrast, hypoxic liver injury with hyper-acute elevation of aminotransferases $>1000$, liver necrosis and coagulopathy has been described only in a handful of cases (Mathurin et al., 1995; Henrion et al., 1997, 2003; Trakada et al., 2004). Patients with OSA-induced liver injury uniformly had obesity hypoventilation syndrome with daytime hypoxemia, and sleep disordered breathing in these cases was characterized by severe hypoxemia with oxyhemoglobin saturation below $70 \%$ for prolonged periods of time. Nevertheless, current clinical evidence demonstrates that liver pathology in OSA by enlarge is not a result of simple liver tissue hypoxia.

\section{IH AND NAFLD: EXPERIMENTAL EVIDENCE}

A mouse model of IH mimicking oxyhemoglobin desaturations in patients with OSA has been utilized with a $\mathrm{FiO}_{2}$ fluctuating between 20.9 and 5\% 60 times/h during the $12 \mathrm{~h}$ light phase (9am to $9 \mathrm{pm}$ ) when $70 \%$ of mouse sleep occurs (Polotsky et al., 2006). $\mathrm{O}_{2}$ swings resulted in reciprocal changes in oxyhemoglobin saturation $\left(\mathrm{SpO}_{2}\right)$ from $95-98 \%$ to mid $60 \%$-low $70 \%$ (Reinke et al., 2011a,b). Lean C57BL/6J mice exposed to such a regimen did not immediately develop liver injury. In fact, lipid peroxidation increased in the liver only after 4 weeks of exposure, but serum aminotransferases remained within the normal range (Jun et al., 2008; Drager et al., 2011). Only after 12 weeks of exposure, lean C57BL/6J mice exhibited a mild increase in serum ALT to $\sim 200 \mathrm{U} / \mathrm{L}$ and exhibited moderate hepatocellular swelling without steatosis or cellular apoptosis (Savransky et al., 2007c). The presence of obesity dramatically exacerbated effects of IH. In C57BL/6J mice with diet-induced obesity (DIO), IH for 4 weeks increased the degree of hepatic steatosis, induced lipid peroxidation on the liver, elevated ALT, AST, and AP levels and exacerbated insulin 
resistance, a hallmark of NASH (Drager et al., 2011). In DIO mice, but not in lean mice, IH increased RNA and protein levels of proinflammatory cytokines TNF- $\alpha$ and MIP-2 in the liver suggesting the progression of hepatic steatosis to steatohepatitis (Drager et al., 2011). IH for 6 months converted diet-induced hepatic steatosis to NASH with liver fibrosis (Savransky et al., 2007a). Thus, experimental evidence suggests that IH per se is not sufficient to cause NAFLD in the mouse model. IH and obesity interact to exacerbate hepatic steatosis converting it to steatohepatitis.

\section{MECHANISIMS OF NAFLD AND NASH IN OSA}

Putative mechanisms by which OSA may promote the development and progression of NAFD are depicted in Figure 2. OSA encompasses several physiological mechanisms which may predispose to NAFLD including negative intra-thoracic pressure swings, sleep fragmentation, hypercapnea, and IH. However, the relationship between NAFLD and IH is the only one which has been studied and will be further discussed. We will first review mechanisms by which IH may lead to hepatic steatosis.

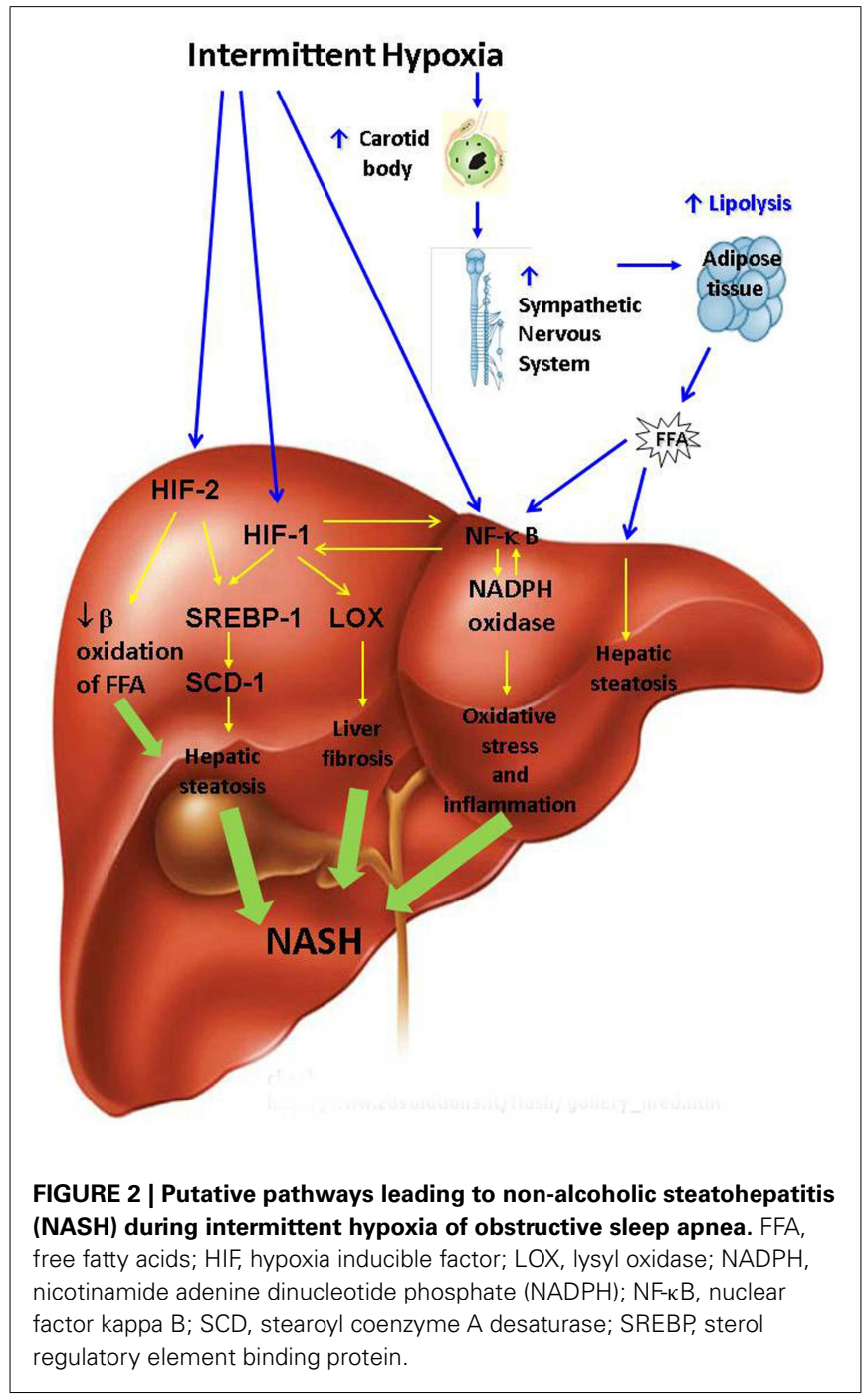

\section{IH AND HEPATIC STEATOSIS}

Intermittent hypoxia may exacerbate hepatic steatosis via systemic and tissue specific mechanisms. Systemic mechanisms are likely mediated via the sympathetic nervous system (SNS). Obesity and insulin resistance are characterized by increased adipocyte mass and increased hormone-sensitive lipase activity, which leads to up-regulation of lipolysis and increased uptake of FFA by the liver (Browning and Horton, 2004). SNS is a major regulator of lipolysis (Jaworski et al., 2007; Bickel et al., 2009; Lafontan and Langin, 2009; Zechner et al., 2009). Human OSA and IH in rodents activate SNS and increase circulating catecholamine levels (Somers et al., 1989, 1995; Carlson et al., 1993; Dimsdale et al., 1995; Fletcher et al., 1995; Hedner et al., 1995; Bao et al., 1997; Narkiewicz et al., 1998, 1999). Activation of the SNS during IH occurs through the hypoxic chemo-reflex in the carotid body and ablation of the carotid sinus nerve prevents IH-induced hypertension (Fletcher et al., 1992a,b; Fletcher, 2001; Prabhakar et al., 2007; Prabhakar and Kumar, 2010). We and others have recently shown that sleep apnea raises circulating FFA levels in proportion to the severity of hypoxia (Barcelo et al., 2011; Jun et al., 2011) suggesting that IH leads to exuberant lipolysis in adipose tissue. The FFA influx into the liver may induce insulin resistance and triglyceride biosynthesis leading to hepatic steatosis (Delarue and Magnan, 2007; Guilherme et al., 2008; Jocken and Blaak, 2008; Neuschwander-Tetri, 2010; Tilg and Moschen, 2010). In addition, high levels of insulin in obese individuals may up-regulate hepatic lipid biosynthesis de novo by activating SREBP-1c (Foretz et al., 1999; Shimomura et al., 1999b) and a SREBP-1-regulated enzyme of triglyceride biosynthesis SCD-1 (Cohen et al., 2002; Biddinger et al., 2005). Exposure to $\mathrm{IH}$ for 5 days to 12 weeks uniformly activated the SREBP-1c axis and downstream SCD-1 in both lean and obese mice inducing triglyceride accumulation in the liver, which was more pronounced in DIO and in mice with leptin-deficient obesity (Li et al., 2005a,b, 2007; Savransky et al., 2007b; Drager et al., 2011). It is conceivable that $\mathrm{IH}$ induces hepatic steatosis by up-regulating hypoxia inducible factors 1 and 2, masters-regulators of metabolic responses to hypoxia composed of constitutively expressed HIF$1 \beta$ and $\mathrm{O}_{2}$ responsive $1 \alpha$ and $2 \alpha$ subunits respectively (Semenza, 2007; Semenza and Prabhakar, 2007; Majmundar et al., 2010). Obesity is associated with liver tissue hypoxia, which may be further exacerbated by IH of OSA (Reinke et al., 2011a) resulting in HIF activation. Partial global deficiency of HIF- $1 \alpha$ of hypoxia inducible factor $1 \alpha$ abolished SREBP- 1 and SCD- 1 up-regulation and prevented triglyceride accumulation in the liver during $\mathrm{IH}(\mathrm{Li}$ et al., 2006). However, HIF-1 is implicated in carotid body activation during IH and the HIF- $1 \alpha$ effect may be mediated systemically via SNS rather than directly on the liver (Peng et al., 2006). Additional insight into the potential role of HIFs in the pathogenesis of hepatic steatosis during $\mathrm{IH}$ has been obtained from mice with deficiency of Von Hippel-Lindau (VHL) tumor suppressive protein in the liver. VHL is required for HIF degradation, therefore VHL mice exhibit a phenotype of constitutive HIF up-regulation (Haase et al., 2001; Rankin et al., 2005). VHL deficient mice have severe hepatic steatosis which was prevented by HIF- $2 \alpha$ but not HIF- $1 \alpha$ knockout suggesting that HIF- 2 contributes to the pathogenesis of hepatic steatosis (Rankin et al., 2009; Qu et al., 2011). 
In the VHL model HIF- $2 \alpha$ up-regulated lipid biosynthetic genes and down-regulated genes of $\beta$-oxidation. However, applicability of findings in the VHL KO model to hepatic steatosis induced by $\mathrm{IH}$ is uncertain. It remains unknown whether up-regulation of lipogenic genes during IH occurs due to direct activation of HIFs in the liver or predominantly due to the FFA flux from adipose tissue.

\section{IH AND NASH}

Putative mechanisms of NAFLD progression to NASH are depicted in Figure 2. FFA flux to the liver induced by IH (Drager et al., 2011; Jun et al., 2011) may up-regulate IкB kinase $\beta$ resulting in phosphorylation and degradation of I $\mathrm{B}$ followed by activation of NF- $\mathrm{B}$ and ensuing synthesis of pro-inflammatory cytokines tumor necrosis factor alpha (TNF- $\alpha$ ), interleukin 6 (IL-6), macrophage inflammatory protein 2 (MIP-2) and others (Kim et al., 2001; Sinha et al., 2004; Boden et al., 2005; Cai et al., 2005). We have previously reported activation of NF-кB in the liver by IH (Savransky et al., 2007c). In the presence of obesity and hepatic steatosis, IH increased mRNA and protein levels of pro-inflammatory cytokines TNF- $\alpha$, IL-1, MIP-2 in liver tissue (Savransky et al., 2007a,b; Drager et al., 2011). It is conceivable that $\mathrm{IH}$ and obesity interact to induce NASH via accelerated adipose tissue lipolysis. However, this hypothesis is yet to be proven in rodent experiments and clinical studies with lipolysis inhibitors.

Intermittent hypoxia may also lead to NASH by up-regulating reactive oxygen species (ROS) generation via NADPH oxidase system (Jun et al., 2008). NADPH oxidase stimulates hepatic stellate cells to produce collagen via angiotensin II leading to liver fibrosis (Bataller et al., 2003; Novitskiy et al., 2006). NADPH oxidase can activate NF-кB (Brar et al., 2003). Reactive oxygen may also directly stimulate NF-кB (Li and Karin, 1999) inducing downstream inflammatory pathways (Ben-Neriah and Karin, 2011). There is a cross-talk between NF-kB and HIF-1 $\alpha$, which mutually activate each other (Walmsley et al., 2005; Scortegagna et al., 2008; Taylor and Cummins, 2009). NF-кB and HIF-1 up-regulate

\section{REFERENCES}

Angulo, P., Keach, J. C., Batts, K. P., and Lindor, K. D. (1999). Independent predictors of liver fibrosis in patients with nonalcoholic steatohepatitis. Hepatology 30, 1356-1362.

Aron-Wisnewsky, J., Minville, C., Tordjman, J., Levy, P., Bouillot, J. L., Basdevant, A., et al. (2012). Chronic intermittent hypoxia is a major trigger for non-alcoholic fatty liver disease in morbid obese. J. Hepatol. 56, 225-233.

Bao, G., Metreveli, N., Li, R., Taylor, A., and Fletcher, E. C. (1997). Blood pressure response to chronic episodic hypoxia: role of the sympathetic nervous system. J. Appl. Physiol. 83, 95-101.

Baranova, A., Lal, P., Birerdinc, A., and Younossi, Z. M. (2011). Non-invasive markers for hepatic

synthesis of collagen, while HIF-1 also induces transcription of lysyl oxidase resulting in cross-linking of collagen (Novitskiy et al., 2004; Manalo et al., 2005; Copple et al., 2009, 2011; Haase, 2009). Paradoxically, HIF-1 may be protective in ischemia-reperfusion liver injury by preventing hepatocyte apoptosis (Schneider et al., 2010; Lehwald et al., 2011; Nath and Szabo, 2012). However, NASH in OSA is a fundamentally different process from ischemiareperfusion injury observed in "shock liver," which is mediated by the intricate interplay of systemic and tissue specific processes described above and in Figure 2. We have previously demonstrated that $\mathrm{IH}$ causes hepatic inflammation and fibrosis in mice with diet-induced hepatic steatosis (Savransky et al., 2007a; Drager et al., 2011). We have also shown that IH causes more severe liver hypoxia in obese mice (Reinke et al., 2011a). It is conceivable that severe liver hypoxia in obese individuals with severe OSA induces NF-kB and HIF-1 in the liver resulting in steatohepatitis and liver fibrosis. However, this hypothesis is yet to be tested.

\section{CONCLUSION}

Obstructive sleep apnea and NAFLD are common complications of obesity. The causality of NAFLD has been linked to obesity, but mechanisms of NAFLD progression to NASH are unknown and there is no effective treatment. Emerging evidence suggests that OSA may contribute to the development and progression of NAFLD to NASH. However, many questions remain unanswered. First, the causal link between OSA and NAFLD has not been established. Prospective clinical studies and a randomized placebo controlled clinical trials of CPAP in patients with NAFLD and NASH will have to be conducted. Second, mechanisms by which OSA and IH may lead to NAFLD and NASH remain unclear. The mouse model of IH will allow to explore such mechanisms utilizing targeted pharmacological interventions (sympathetic blockade, antioxidants, and lipolysis inhibitors) and transgenic animals with liver specific knockouts of gene candidates (HIFs, NADPH oxidase, $\mathrm{NF}-\kappa \mathrm{B})$.

NF-kappaB as the matchmaker. Nat. Immunol. 12, 715-723.

Bergamini, C. M., Gambetti, S., Dondi, A., and Cervellati, C. (2004). Oxygen, reactive oxygen species and tissue damage. Curr. Pharm. Des. 10, 1611-1626.

Bickel, P. E., Tansey, J. T., and Welte, M. A. (2009). PAT proteins, an ancient family of lipid droplet proteins that regulate cellular lipid stores. Biochim. Biophys. Acta 1791, 419-440.

Biddinger, S. B., Almind, K., Miyazaki, M., Kokkotou, E., Ntambi, J. M., and Kahn, C. R. (2005). Effects of diet and genetic background on sterol regulatory element-binding protein1c, stearoyl-CoA desaturase 1 , and the development of the metabolic syndrome. Diabetes 54, 1314-1323.

Boden, G., She, P., Mozzoli, M., Cheung, P., Gumireddy, K., Reddy, P., et al. (2005). Free fatty acids produce insulin resistance and activate the proinflammatory nuclear factorkappaB pathway in rat liver. Diabetes 54, 3458-3465.

Bonekamp, S., Kamel, I., Solga, S., and Clark, J. (2009). Can imaging modalities diagnose and stage hepatic fibrosis and cirrhosis accurately? J. Hepatol. 50, 17-35.

Bonsignore, M. R., Esquinas, C., Barcelo, A., Sanchez-de-la-Torre, M., Paterno, A., Duran-Cantolla, J., et al. (2012). Metabolic syndrome, insulin resistance and sleepiness in real-life obstructive sleep apnoea. Eur. Respir. J. 39, 1136-1143.

Brar, S. S., Kennedy, T. P., Quinn, M., and Hoidal, J. R. (2003). Redox signaling of NF-kappaB by membrane $\mathrm{NAD}(\mathrm{P}) \mathrm{H}$ oxidases in normal and malignant cells. Protoplasma 221, 117-127. 
Browning, J. D., and Horton, J. D. (2004). Molecular mediators of hepatic steatosis and liver injury. $J$. Clin. Invest. 114, 147-152.

Browning, J. D., Szczepaniak, L. S., Dobbins, R., Nuremberg, P., Horton, J. D., Cohen, J. C., et al. (2004). Prevalence of hepatic steatosis in an urban population in the United States: impact of ethnicity. Hepatology 40, 1387-1395.

Bugianesi, E., Leone, N., Vanni, E., Marchesini, G., Brunello, F., Carucci, P., et al. (2002). Expanding the natural history of nonalcoholic steatohepatitis: from cryptogenic cirrhosis to hepatocellular carcinoma. Gastroenterology 123, 134-140.

Cai, D., Yuan, M., Frantz, D. F., Melendez, P. A., Hansen, L., Lee, J., et al. (2005). Local and systemic insulin resistance resulting from hepatic activation of IKK-beta and NFkappaB. Nat. Med. 11, 183-190.

Caldwell, S. H., Oelsner, D. H., Iezzoni, J. C., Hespenheide, E. E., Battle, E. H., and Driscoll, C. J. (1999). Cryptogenic cirrhosis: clinical characterization and risk factors for underlying disease. Hepatology 29, 664-669.

Carlson, J. T., Hedner, J., Elam, M., Ejnell, H., Sellgren, J., and Wallin, B. G. (1993). Augmented resting sympathetic activity in awake patients with obstructive sleep apnea. Chest 103, 1763-1768.

Carmiel-Haggai, M., Cederbaum, A. I., and Nieto, N. (2005). A high-fat diet leads to the progression of nonalcoholic fatty liver disease in obese rats. FASEB J. 19, 136-138.

Chin, K., Nakamura, T., Takahashi, K., Sumi, K., Ogawa, Y., Masuzaki, H., et al. (2003). Effects of obstructive sleep apnea syndrome on serum aminotransferase levels in obese patients. Am. J. Med. 114, 370-376.

Clark, J. M. (2006). The epidemiology of nonalcoholic fatty liver disease in adults. J. Clin. Gastroenterol. 40, S5-S10.

Clark, J. M., and Diehl, A. M. (2003). Nonalcoholic fatty liver disease: an underrecognized cause of cryptogenic cirrhosis. JAMA 289, 3000-3004.

Cohen, P., Miyazaki, M., Socci, N. D., Hagge-Greenberg, A., Liedtke, W., Soukas, A. A., et al. (2002). Role for stearoyl-CoA desaturase-1 in leptinmediated weight loss. Science 297, 240-243.

Copple, B. L., Bai, S., Burgoon, L. D., and Moon, J. O. (2011). Hypoxiainducible factor-1alpha regulates the expression of genes in hypoxic hepatic stellate cells important for collagen deposition and angiogenesis. Liver Int. 31, 230-244.

Copple, B. L., Bustamante, J. J., Welch, T. P., Kim, N. D., and Moon, J. O. (2009). Hypoxia-inducible factordependent production of profibrotic mediators by hypoxic hepatocytes. Liver Int. 29, 1010-1021.

Daltro, C., Cotrim, H. P., Alves, E., de Freitas, L. A., Araujo, L., Boente, L., et al. (2010). Nonalcoholic fatty liver disease associated with obstructive sleep apnea: just a coincidence? Obes. Surg. 20, 1536-1543.

Davies, M. N., O'Callaghan, B. L., and Towle, H. C. (2008). Glucose activates ChREBP by increasing its rate of nuclear entry and relieving repression of its transcriptional activity. $J$. Biol. Chem. 283, 24029-24038.

Day, C. P., and James, O. F. (1998). Steatohepatitis: a tale of two "hits"? Gastroenterology 114, 842-845.

Delarue, J., and Magnan, C. (2007). Free fatty acids and insulin resistance. Curr. Opin. Clin. Nutr. Metab. Care 10, 142-148.

Dentin, R., Benhamed, F., Hainault, I., Fauveau, V., Foufelle, F., Dyck, J. R., et al. (2006). Liver-specific inhibition of ChREBP improves hepatic steatosis and insulin resistance in ob/ob mice. Diabetes 55, 2159-2170.

Diehl, A. M. (2005). Lessons from animal models of NASH. Hepatol. Res. 33, 138-144.

Dimsdale, J. E., Coy, T., Ziegler, M. G., ncoli-Israel, S., and Clausen, J. (1995). The effect of sleep apnea on plasma and urinary catecholamines. Sleep 18, 377-381.

Dixon, J. B., Bhathal, P. S., and O'Brien, P. E. (2001). Nonalcoholic fatty liver disease: predictors of nonalcoholic steatohepatitis and liver fibrosis in the severely obese. Gastroenterology 121, 91-100.

Drager, L. F., Jun, J. C., and Polotsky, V. Y. (2010a). Metabolic consequences of intermittent hypoxia: relevance to obstructive sleep apnea. Best Pract. Res. Clin. Endocrinol. Metab. 24, 843-851.

Drager, L. F., Lopes, H. F., MakiNunes, C., Trombetta, I. C., ToschiDias, E., Alves, M. J., et al. (2010b). The impact of obstructive sleep apnea on metabolic and inflammatory markers in consecutive patients with metabolic syndrome. PLOS ONE 5, e12065. doi:10.1371/journal.pone.0012065

Drager, L. F., Li, J., Reinke, C., BevansFonti, S., Jun, J. C., and Polotsky, V. Y. (2011). Intermittent hypoxia exacerbates metabolic effects of diet-induced obesity. Obesity (Silver Spring) 19, 2167-2174.
Fletcher, E. C. (2001). Invited review: physiological consequences of intermittent hypoxia: systemic blood pressure. J. Appl. Physiol. 90, 1600-1605.

Fletcher, E. C., Bao, G., and Miller, C. C. III. (1995). Effect of recurrent episodic hypocapnic, eucapnic, and hypercapnic hypoxia on systemic blood pressure. J. Appl. Physiol. 78, 1516-1521.

Fletcher, E. C., Lesske, J., Behm, R. Miller, C. C., Stauss, H., and Unger, T. (1992a). Carotid chemoreceptors, systemic blood pressure, and chronic episodic hypoxia mimicking sleep apnea. J. Appl. Physiol. 72, 1978-1984.

Fletcher, E. C., Lesske, J., Culman, J., Miller, C. C., and Unger, T. (1992b). Sympathetic denervation blocks blood pressure elevation in episodic hypoxia. Hypertension 20 612-619.

Foretz, M., Pacot, C., Dugail, I., Lemarchand, P., Guichard, C., Le, L. X., et al. (1999). ADD1/SREBP-1c is required in the activation of hepatic lipogenic gene expression by glucose. $\mathrm{Mol}$. Cell. Biol. 19, 3760-3768.

Friedrich-Rust, M., Hadji-Hosseini, H., Kriener, S., Herrmann, E., Sircar, I., Kau, A., et al. (2010). Transient elastography with a new probe for obese patients for non-invasive staging of non-alcoholic steatohepatitis. Eur. Radiol. 20, 2390-2396.

Gami, A. S., Howard, D. E., Olson, E. J. and Somers, V. K. (2005). Day-night pattern of sudden death in obstructive sleep apnea. N. Engl. J. Med. 352, 1206-1214.

Gastaut, H., Tassinari, C. A., and Duron B. (1966). Polygraphic study of the episodic diurnal and nocturnal (hypnic and respiratory) manifestations of the Pickwick syndrome. Brain Res. 1, 167-186.

George, J., Pera, N., Phung, N., Leclercq I., Yun, H. J., and Farrell, G. (2003). Lipid peroxidation, stellate cell activation and hepatic fibrogenesis in a rat model of chronic steatohepatitis. J. Hepatol. 39, 756-764.

Gude, F., Rey-Garcia, J., FernandezMerino, C., Meijide, L., GarciaOrtiz, L., Zamarron, C., et al. (2009). Serum levels of gammaglutamyl transferase are associated with markers of nocturnal hypoxemia in a general adult population. Clin. Chim. Acta 407, 67-71.

Guilherme, A., Virbasius, J. V., Puri, V., and Czech, M. P. (2008). Adipocyte dysfunctions linking obesity to insulin resistance and type 2 diabetes. Nat. Rev. Mol. Cell Biol. 9, 367-377.
Haase, V. H. (2009). Pathophysiological Consequences of HIF Activation: HIF as a modulator of fibrosis. Ann. N. Y. Acad. Sci. 1177, 57-65.

Haase, V. H., Glickman, J. N., Socolovsky, M., and Jaenisch, R. (2001). Vascular tumors in livers with targeted inactivation of the von Hippel-Lindau tumor suppressor. Proc. Natl. Acad. Sci. U.S.A. 98 1583-1588.

Hedner, J., Darpo, B., Ejnell, H., Carlson, J., and Caidahl, K. (1995). Reduction in sympathetic activity after long-term CPAP treatment in sleep apnoea: cardiovascular implications. Eur. Respir. J. 8, 222-229.

Henrion, J., Colin, L., Schapira, M., and Heller, F. R. (1997). Hypoxic hepatitis caused by severe hypoxemia from obstructive sleep apnea. J. Clin. Gastroenterol. 24, 245-249.

Henrion, J., Schapira, M., Luwaert, R., Colin, L., Delannoy, A., and Heller, F. R. (2003). Hypoxic hepatitis: clinical and hemodynamic study in 142 consecutive cases. Medicine (Baltimore) 82, 392-406.

Hernaez, R., Lazo, M., Bonekamp, S., Kamel, I., Brancati, F. L., Guallar, E., et al. (2011). Diagnostic accuracy and reliability of ultrasonography for the detection of fatty liver: a meta-analysis. Hepatology 54, 1082-1090.

Hilden, M., Christoffersen, P., Juhl, E., and Dalgaard, J. B. (1977). Liver histology in a "normal" population - examinations of 503 consecutive fatal traffic casualties. Scand. J. Gastroenterol. 12, 593-597.

Hoyos, C. M., Killick, R., Yee, B. J., Phillips, C. L., Grunstein, R. R., and Liu, P. Y. (2012). Cardiometabolic changes after continuous positive airway pressure for obstructive sleep apnoea: a randomised shamcontrolled study. Thorax. PMID: 22561530. [Epub ahead of print].

Iiyori, N., Alonso, L. C., Li, J., Sanders, M. H., Garcia-Ocana, A., O’Doherty, R. M., et al. (2007). Intermittent hypoxia causes insulin resistance in lean mice independent of autonomic activity. Am. J. Respir. Crit. Care Med. $175,851-857$.

Iizuka, K., Bruick, R. K., Liang, G., Horton, J. D., and Uyeda, K. (2004). Deficiency of carbohydrate response element-binding protein (ChREBP) reduces lipogenesis as well as glycolysis. Proc. Natl. Acad. Sci. U.S.A. 101, 7281-7286.

Jaworski, K., Sarkadi-Nagy, E., Duncan, R. E., Ahmadian, M., and Sul, H. S. (2007). Regulation of triglyceride metabolism. IV. Hormonal 
regulation of lipolysis in adipose tissue. Am. J. Physiol. Gastrointest. Liver Physiol. 293, G1-G4.

Jocken, J. W., and Blaak, E. E. (2008). Catecholamine-induced lipolysis in adipose tissue and skeletal muscle in obesity. Physiol. Behav. 94, 219-230.

Jouet, P., Sabate, J. M., Maillard, D., Msika, S., Mechler, C., Ledoux, S., et al. (2007). Relationship between obstructive sleep apnea and liver abnormalities in morbidly obese patients: a prospective study. Obes. Surg. 17, 478-485.

Jun, J., and Polotsky, V. Y. (2009). Metabolic consequences of sleepdisordered breathing. ILAR J. 50, 289-306.

Jun, J., Savransky, V., Nanayakkara, A., Bevans, S., Li, J., Smith, P. L., et al. (2008). Intermittent hypoxia has organ-specific effects on oxidative stress. Am. J. Physiol. Regul. Integr. Comp. Physiol. 295, R1274-R1281.

Jun, J. C., Drager, L. F., Najjar, S. S., Gottlieb, S. S., Brown, C. D., Smith, P. L., et al. (2011). Effects of sleep apnea on nocturnal free fatty acids in subjects with heart failure. Sleep 34, 1207-1213.

Kallwitz, E. R., Herdegen, J., Madura, J., Jakate, S., and Cotler, S. J. (2007). Liver enzymes and histology in obese patients with obstructive sleep apnea. J. Clin. Gastroenterol. 41, 918-921.

Kashi, M. R., Torres, D. M., and Harrison, S. A. (2008). Current and emerging therapies in nonalcoholic fatty liver disease. Semin. Liver Dis. $28,396-406$.

Kheirandish-Gozal, L., Sans, C. O., Kheirandish, E., and Gozal, D. (2008). Elevated serum aminotransferase levels in children at risk for obstructive sleep apnea. Chest 133, 92-99.

Kim, C. W., Chang, Y., Sung, E., Shin, H., and Ryu, S. (2012). Serum ferritin levels predict incident non-alcoholic fatty liver disease in healthy Korean men. Metabolism 61, 1182-1188.

Kim, J. K., Kim, Y. J., Fillmore, J. J., Chen, Y., Moore, I., Lee, J., et al. (2001). Prevention of fat-induced insulin resistance by salicylate. J. Clin. Invest. 108, 437-446.

Kleiner, D. E., Brunt, E. M., Van, N. M., Behling, C., Contos, M. J., Cummings, O. W., et al. (2005). Design and validation of a histological scoring system for nonalcoholic fatty liver disease. Hepatology 41, 1313-1321.

Kohler, M., Pepperell, J. C., Davies, R. J., and Stradling, J. R. (2009). Continuous positive airway pressure and liver enzymes in obstructive sleep apnoea: data from a randomized controlled trial. Respiration 78, 141-146.

Kowdley, K. V., Belt, P., Wilson, L. A., Yeh, M. M., Neuschwander-Tetri, B. A., Chalasani, N., et al. (2012). Serum ferritin is an independent predictor of histologic severity and advanced fibrosis in patients with nonalcoholic fatty liver disease. Hepatology $55,77-85$.

Lafontan, M., and Langin, D. (2009). Lipolysis and lipid mobilization in human adipose tissue. Prog. Lipid Res. 48, 275-297.

Laurent, A., Nicco, C., Tran, V. N., Borderie, D., Chereau, C., Conti, F., et al. (2004). Pivotal role of superoxide anion and beneficial effect of antioxidant molecules in murine steatohepatitis. Hepatology 39, 1277-1285.

Lavie, L., and Polotsky, V. (2009). Cardiovascular aspects in obstructive sleep Apnea syndrome - molecular issues, hypoxia and cytokine profiles. Respiration 78, 361-370.

Lehwald, N., Tao, G. Z., Jang, K. Y., Sorkin, M., Knoefel, W. T., and Sylvester, K. G. (2011). Wnt-betacatenin signaling protects against hepatic ischemia and reperfusion injury in mice. Gastroenterology 141 , 707-18, 718 .

Levy, P., Bonsignore, M. R., and Eckel, J. (2009). Sleep, sleep-disordered breathing and metabolic consequences. Eur. Respir. J. 34, 243-260.

Li, J., Bosch-Marce, M., Nanayakkara, A., Savransky, V., Fried, S. K., Semenza, G. L., et al. (2006). Altered metabolic responses to intermittent hypoxia in mice with partial deficiency of hypoxia-inducible factor-1alpha. Physiol. Genomics 25, 450-457.

Li, J., Grigoryev, D. N., Ye, S. Q., Thorne, L., Schwartz, A. R., Smith, P. L., et al. (2005a). Chronic intermittent hypoxia upregulates genes of lipid biosynthesis in obese mice. J. Appl. Physiol. 99, 1643-1648.

Li, J., Thorne, L. N., Punjabi, N. M., Sun, C. K., Schwartz, A. R., Smith, P. L., et al. (2005b). Intermittent hypoxia induces hyperlipidemia in lean mice. Circ. Res. 97, 698-706.

Li, J., Savransky, V., Nanayakkara, A., Smith, P. L., O'Donnell, C. P., and Polotsky, V. Y. (2007). Hyperlipidemia and lipid peroxidation are dependent on the severity of chronic intermittent hypoxia. J. Appl. Physiol. 102, 557-563.

Li, N., and Karin, M. (1999). Is NFkappaB the sensor of oxidative stress? FASEB J. 13, 1137-1143.

Li, Z. Z., Berk, M., McIntyre, T. M., and Feldstein, A. E. (2009). Hepatic lipid partitioning and liver damage in nonalcoholic fatty liver disease: role of stearoyl-CoA desaturase. $J$. Biol. Chem. 284, 5637-5644.

Licata, A., Nebbia, M. E., Cabibbo, G., Iacono, G. L., Barbaria, F., Brucato, V., et al. (2009). Hyperferritinemia is a risk factor for steatosis in chronic liver disease. World J. Gastroenterol. 15, 2132-2138.

Louis, M., and Punjabi, N. M. (2009). Effects of acute intermittent hypoxia on glucose metabolism in awake healthy volunteers. J. Appl. Physiol. 106, 1538-1544.

Ludwig, J., McGill, D. B., and Lindor, K. D. (1997). Review: nonalcoholic steatohepatitis. J. Gastroenterol. Hepatol. 12, 398-403.

Ma, L., Robinson, L. N., and Towle, H. C. (2006). ChREBP*Mlx is the principal mediator of glucose-induced gene expression in the liver. J. Biol. Chem. 281, 28721-28730.

Majmundar, A. J., Wong, W. J., and Simon, M. C. (2010). Hypoxiainducible factors and the response to hypoxic stress. Mol. Cell 40, 294-309.

Manalo, D. J., Rowan, A., Lavoie, T., Natarajan, L., Kelly, B. D., Ye, S. Q., et al. (2005). Transcriptional regulation of vascular endothelial cell responses to hypoxia by HIF-1. Blood 105, 659-669.

Manousou, P., Kalambokis, G., Grillo, F., Watkins, J., Xirouchakis, E. Pleguezuelo, M., et al. (2011). Serum ferritin is a discriminant marker for both fibrosis and inflammation in histologically proven non-alcoholic fatty liver disease patients. Liver Int 31, 730-739.

Marshall, N. S., Wong, K. K., Liu, P. Y., Cullen, S. R., Knuiman, M. W., and Grunstein, R. R. (2008). Sleep apnea as an independent risk factor for allcause mortality: the Busselton health study. Sleep 31, 1079-1085.

Mathurin, P., Durand, F., Ganne, N., Mollo, J. L., Lebrec, D., Degott, C., et al. (1995). Ischemic hepatitis due to obstructive sleep apnea. Gastroenterology 109, 1682-1684.

McCullough, A. J. (2004). The clinical features, diagnosis and natural history of nonalcoholic fatty liver disease. Clin. Liver Dis. 8, 521-533, viii.

McCullough, A. J. (2006). Pathophysiology of nonalcoholic steatohepatitis. J. Clin. Gastroenterol. 40, S17-S29.

Mishra, P., Nugent, C., Afendy, A., Bai, C., Bhatia, P., Afendy, M., et al. (2008). Apnoeic-hypopnoeic episodes during obstructive sleep apnoea are associated with histological nonalcoholic steatohepatitis. Liver Int. 28 , 1080-1086.

Myers, R. P., Pollett, A., Kirsch, R., Pomier-Layrargues, G., Beaton, M., Levstik, M., et al. (2012a). Controlled attenuation parameter (CAP): a noninvasive method for the detection of hepatic steatosis based on transient elastography. Liver Int. 32, 902-910.

Myers, R. P., Pomier-Layrargues, G., Kirsch, R., Pollett, A., Duarte-Rojo, A., Wong, D., et al. (2012b). Feasibility and diagnostic performance of the FibroScan XL probe for liver stiffness measurement in overweight and obese patients. Hepatology 55, 199-208.

Narkiewicz, K., Kato, M., Phillips, B. G., Pesek, C. A., Davison, D. E., and Somers, V. K. (1999). Nocturnal continuous positive airway pressure decreases daytime sympathetic traffic in obstructive sleep apnea. Circulation 100, 2332-2335.

Narkiewicz, K., van de Borne, P. J., Cooley, R. L., Dyken, M. E., and Somers, V. K. (1998). Sympathetic activity in obese subjects with and without obstructive sleep apnea. Circulation $98,772-776$.

Nath, B., and Szabo, G. (2012). Hypoxia and hypoxia inducible factors: diverse roles in liver diseases. Hepatology 55, 622-633.

Neuschwander-Tetri, B. A. (2010). Hepatic lipotoxicity and the pathogenesis of nonalcoholic steatohepatitis: the central role of nontriglyceride fatty acid metabolites. Hepatology 52, 774-788.

Nomura, H., Kashiwagi, S., Hayashi, J., Kajiyama, W., Tani, S., and Goto, M. (1988). Prevalence of fatty liver in a general population of Okinawa, Japan. Jpn. J. Med. 27, 142-149.

Norman, D., Bardwell, W. A., Arosemena, F., Nelesen, R., Mills, P. J., Loredo, J. S., et al. (2008). Serum aminotransferase levels are associated with markers of hypoxia in patients with obstructive sleep apnea. Sleep 31, 121-126.

Novitskiy, G., Potter, J. J., RennieTankersley, L., and Mezey, E. (2004). Identification of a novel NFkappaB-binding site with regulation of the murine alpha2(I) collagen promoter. J. Biol. Chem. 279, 15639-15644.

Novitskiy, G., Potter, J. J., Wang, L., and Mezey, E. (2006). Influences of reactive oxygen species and nitric oxide on hepatic fibrogenesis. Liver Int. 26, 1248-1257.

Oliveira, C. P., Faintuch, J., Rascovski, A., Furuya, C. K. Jr., Bastos, M. S., 
Matsuda, M., et al. (2005). Lipid peroxidation in bariatric candidates with nonalcoholic fatty liver disease (NAFLD) - preliminary findings. Obes. Surg. 15, 502-505.

Patel, K. D., Abeysekera, K. W., Marlais, M., McPhail, M. J., Thomas, H. C., Fitzpatrick, J. A., et al. (2011). Recent advances in imaging hepatic fibrosis and steatosis. Expert Rev. Gastroenterol. Hepatol. 5, 91-104.

Peng, Y. J., Yuan, G., Ramakrishnan, D., Sharma, S. D., Bosch-Marce, M., Kumar, G. K., et al. (2006). Heterozygous HIF-1\{alpha\} deficiency impairs carotid body-mediated systemic responses and reactive oxygen species generation in mice exposed to intermittent hypoxia. J. Physiol. (Lond.) 577, 705-716.

Polotsky, V. Y., Li, J., Punjabi, N. M., Rubin, A. E., Smith, P. L., Schwartz, A. R., et al. (2003). Intermittent hypoxia increases insulin resistance in genetically obese mice. J. Physiol. (Lond.) 552, 253-264.

Polotsky, V. Y., Patil, S. P., Savransky, V., Laffan, A., Fonti, S., Frame, L. A., et al. (2009). Obstructive sleep apnea, insulin resistance, and steatohepatitis in severe obesity. Am. J. Respir. Crit. Care Med. 179, 228-234.

Polotsky, V. Y., Rubin, A. E., Balbir, A., Dean, T., Smith, P. L., Schwartz, A. R., et al. (2006). Intermittent hypoxia causes REM sleep deficits and decreases EEG delta power in NREM sleep in the C57BL/6 mouse. Sleep Med. 7, 7-16.

Postic, C., Dentin, R., Denechaud, P. D., and Girard, J. (2007). ChREBP, a transcriptional regulator of glucose and lipid metabolism. Annu. Rev. Nutr. 27, 179-192.

Poynard, T., Lassailly, G., Diaz, E., Clement, K., Caiazzo, R., Tordjman, J., et al. (2012). Performance of biomarkers FibroTest, ActiTest, SteatoTest, and NashTest in patients with severe obesity: meta analysis of individual patient data. PLoS ONE 7, e30325. doi:10.1371/journal.pone.0030325

Prabhakar, N. R., Dick, T. E., Nanduri, J., and Kumar, G. K. (2007). Systemic, cellular and molecular analysis of chemoreflex-mediated sympathoexcitation by chronic intermittent hypoxia. Exp. Physiol. 92, 39-44.

Prabhakar, N. R., and Kumar, G. K. (2010). Mechanisms of sympathetic activation and blood pressure elevation by intermittent hypoxia. Respir. Physiol. Neurobiol. 174, 156-161.

Punjabi, N. M., Caffo, B. S., Goodwin, J. L., Gottlieb, D. J., Newman, A. B., O'Connor, G. T., et al. (2009). Sleep-disordered breathing and mortality: a prospective cohort study. PLoS Med. 6, el000132. doi:10.1371/journal.pmed.1000132

Punjabi, N. M., Sorkin, J. D., Katzel, L. I., Goldberg, A. P., Schwartz, A. R., and Smith, P. L. (2002). Sleep-disordered breathing and insulin resistance in middle-aged and overweight men. Am. J. Respir. Crit. Care. Med. 165, 677-682.

Qu, A., Taylor, M., Xue, X., Matsubara, T., Metzger, D., Chambon, P., et al. (2011). Hypoxia-inducible transcription factor 2 alpha promotes steatohepatitis through augmenting lipid accumulation, inflammation, and fibrosis. Hepatology 54, 472-483.

Rankin, E. B., Higgins, D. F., Walisser, J. A., Johnson, R. S., Bradfield, C. A., and Haase, V. H. (2005). Inactivation of the arylhydrocarbon receptor nuclear translocator (Arnt) suppresses von Hippel-Lindau diseaseassociated vascular tumors in mice. Mol. Cell. Biol. 25, 3163-3172.

Rankin, E. B., Rha, J., Selak, M. A., Unger, T. L., Keith, B., Liu, Q., et al. (2009). Hypoxia-inducible factor 2 regulates hepatic lipid metabolism. Mol. Cell. Biol. 29, 4527-4538.

Reinke, C., Bevans-Fonti, S., Drager, L. F., Shin, M. K., and Polotsky, V. Y. (2011a). Effects of different acute hypoxic regimens on tissue oxygen profiles and metabolic outcomes. $J$. Appl. Physiol. 111, 881-890.

Reinke, C., Bevans-Fonti, S., Grigoryev, D. N., Drager, L. F., Myers, A. C., Wise, R. A., et al. (2011b). Chronic intermittent hypoxia induces lung growth in adult mice. Am. J. Physiol. Lung Cell Mol. Physiol. 300, L266L273.

Robertson, G., Leclercq, I., and Farrell, G. C. (2001). Nonalcoholic steatosis and steatohepatitis. II. Cytochrome P-450 enzymes and oxidative stress. Am. J. Physiol. Gastrointest. Liver Physiol. 281, G1135-G1139.

Robinson, G. V., Pepperell, J. C., Segal, H. C., Davies, R. J., and Stradling, J. R. (2004). Circulating cardiovascular risk factors in obstructive sleep apnoea: data from randomised controlled trials. Thorax 59, 777-782.

Saibara, T., Nozaki, Y., Nemoto, Y., Ono, M., and Onishi, S. (2002). Low socioeconomic status and coronary artery disease. Lancet 359, 980.

Samuel, V. T., Liu, Z. X., Qu, X., Elder, B. D., Bilz, S., Befroy, D., et al. (2004). Mechanism of hepatic insulin resistance in non-alcoholic fatty liver disease. J. Biol. Chem. 279, 32345-32353.

Sanyal, A. J., Chalasani, N., Kowdley, K. V., McCullough, A., Diehl, A. M.,
Bass, N. M., et al. (2010). Pioglitazone, vitamin E, or placebo for nonalcoholic steatohepatitis. N. Engl. J. Med. 362, 1675-1685.

Savage, D. B., Petersen, K. F., and Shulman, G. I. (2007). Disordered lipid metabolism and the pathogenesis of insulin resistance. Physiol. Rev. 87, 507-520.

Savransky, V., Bevans, S., Nanayakkara, A., Li, J., Smith, P. L., Torbenson, M. S., et al. (2007a). Chronic intermittent hypoxia causes hepatitis in a mouse model of dietinduced fatty liver. Am. J. Physiol. Gastrointest. Liver Physiol. 293 G871-G877.

Savransky, V., Nanayakkara, A., Li, J., Bevans, S., Smith, P. L., Rodriguez, A., et al. (2007b). Chronic intermittent hypoxia induces atherosclerosis. Am. J. Respir. Crit. Care Med. 175, 1290-1297.

Savransky, V., Nanayakkara, A., Vivero, A., Li, J., Bevans, S., Smith, P. L., et al. (2007c). Chronic intermittent hypoxia predisposes to liver injury. Hepatology 45, 1007-1013.

Schneider, M., Van, G. K., Fraisl, P., Kiss, J., Aragones, J., Mazzone, M., et al. (2010). Loss or silencing of the PHD1 prolyl hydroxylase protects livers of mice against ischemia/reperfusion injury. Gastroenterology 138, 1143-1154.

Scortegagna, M., Cataisson, C., Martin, R. J., Hicklin, D. J., Schreiber, R. D., Yuspa, S. H., et al. (2008). HIF-lalpha regulates epithelial inflammation by cell autonomous NFkappaB activation and paracrine stromal remodeling. Blood 111, 3343-3354.

Seki, S., Kitada, T., and Sakaguchi, H. (2005). Clinicopathological significance of oxidative cellular damage in non-alcoholic fatty liver diseases. Hepatol. Res. 33, 132-134.

Semenza, G. L. (2007). Life with oxygen. Science 318, 62-64.

Semenza, G. L., and Prabhakar, N. R. (2007). HIF-1-dependent respiratory, cardiovascular, and redox responses to chronic intermittent hypoxia. Antioxid Redox Signal 9, 1391-1396.

Sharma, S. K., Agrawal, S., Damodaran, D., Sreenivas, V., Kadhiravan, T., Lakshmy, R., et al. (2011). CPAP for the metabolic syndrome in patients with obstructive sleep apnea. N. Engl. J. Med. 365, 2277-2286.

Shimomura, I., Bashmakov, Y., and Horton, J. D. (1999a). Increased levels of nuclear SREBP-1c associated with fatty livers in two mouse models of diabetes mellitus. J. Biol. Chem. 274, 30028-30032.
Shimomura, I., Bashmakov, Y., Ikemoto, S., Horton, J. D., Brown, M. S., and Goldstein, J. L. (1999b). Insulin selectively increases SREBP1c mRNA in the livers of rats with streptozotocin-induced diabetes. Proc. Natl. Acad. Sci. U.S.A. 96, 13656-13661.

Shimomura, I., Hammer, R. E., Richardson, J. A., Ikemoto, S., Bashmakov, Y., Goldstein, J. L., et al. (1998) Insulin resistance and diabetes mellitus in transgenic mice expressing nuclear SREBP-1c in adipose tissue: model for congenital generalized lipodystrophy. Genes Dev. 12, 3182-3194.

Shpirer, I., Copel, L., Broide, E., and Elizur, A. (2010). Continuous positive airway pressure improves sleep apnea associated fatty liver. Lung 188, 301-307.

Singh, H., Pollock, R., Uhanova, J., Kryger, M., Hawkins, K., and Minuk, G. Y. (2005). Symptoms of obstructive sleep apnea in patients with nonalcoholic fatty liver disease. Dig. Dis. Sci. 50, 2338-2343.

Sinha, S., Perdomo, G., Brown, N. F., and O'Doherty, R. M. (2004). Fatty acid-induced insulin resistance in L6 myotubes is prevented by inhibition of activation and nuclear localization of nuclear factor kappa B. J. Biol. Chem. 279, 41294-41301.

Sivam, S., Phillips, C. L., Trenell, M. I., Yee, B. J., Liu, P. Y., Wong, K. K., et al. (2012). Effects of 8 weeks of CPAP on abdominal adiposity in obstructive sleep apnoea. Eur. Respir. J. 40, 913-918.

Somers, V. K., Dyken, M. E., Clary M. P., and Abboud, F. M. (1995). Sympathetic neural mechanisms in obstructive sleep apnea. J. Clin. Invest. 96, 1897-1904.

Somers, V. K., Mark, A. L., Zavala, D. C., and Abboud, F. M. (1989). Contrasting effects of hypoxia and hypercapnia on ventilation and sympathetic activity in humans. J. Appl. Physiol. 67, 2101-2106.

Springer, F., MacHann, J., Claussen, C. D., Schick, F., and Schwenzer, N. F. (2010). Liver fat content determined by magnetic resonance imaging and spectroscopy. World J. Gastroenterol. $16,1560-1566$.

Tanne, F., Gagnadoux, F., Chazouilleres, O., Fleury, B., Wendum, D., Lasnier, E., et al. (2005). Chronic liver injury during obstructive sleep apnea. Hepatology 41, 1290-1296.

Tatsumi, K., and Saibara, T. (2005). Effects of obstructive sleep apnea syndrome on hepatic steatosis and nonalcoholic steatohepatitis. Hepatol. Res. 33, 100-104. 
Taylor, C. T., and Cummins, E. P. (2009). The role of NF-kappaB in hypoxiainduced gene expression. Ann. N. Y. Acad. Sci. 1177, 178-184.

Tilg, H., and Moschen, A. R. (2010). Evolution of inflammation in nonalcoholic fatty liver disease: the multiple parallel hits hypothesis. Hepatology 52, 1836-1846.

Torres, D. M., and Harrison, S. A. (2008). Diagnosis and therapy of nonalcoholic steatohepatitis. Gastroenterology 134, 1682-1698.

Trakada, G., Gogos, C., Tsiamita, M., Siagris, D., Goumas, P., and Spiropoulos, K. (2004). A case of ischemic hepatitis. Sleep Breath 8, 155-159.

Tufik, S., Santos-Silva, R., Taddei, J. A., and Bittencourt, L. R. (2010). Obstructive sleep apnea syndrome in the Sao Paulo Epidemiologic Sleep Study. Sleep Med. 11, 441-446.

Vgontzas, A. N., Papanicolaou, D. A., Bixler, E. O., Hopper, K., Lotsikas, A., Lin, H. M., et al. (2000). Sleep apnea and daytime sleepiness and fatigue: relation to visceral obesity, insulin resistance, and hypercytokinemia.
J. Clin. Endocrinol. Metab. 85, 1151-1158.

Vuppalanchi, R., and Chalasani, N. (2009). Nonalcoholic fatty liver disease and nonalcoholic steatohepatitis: selected practical issues in their evaluation and management. Hepatology 49, 306-317.

Walmsley, S. R., Print, C., Farahi, N., Peyssonnaux, C., Johnson, R. S., Cramer, T., et al. (2005). Hypoxia-induced neutrophil survival is mediated by HIF-1alpha-dependent NF-kappaB activity. J. Exp. Med. 201, 105-115.

Yaggi, H. K., Concato, J., Kernan, W. N., Lichtman, J. H., Brass, L. M., and Mohsenin, V. (2005). Obstructive sleep apnea as a risk factor for stroke and death. N. Engl. J. Med. 353, 2034-2041.

Yamaguchi, K., Yang, L., McCall, S., Huang, J., Yu, X. X., Pandey, S. K. et al. (2007). Inhibiting triglyceride synthesis improves hepatic steatosis but exacerbates liver damage and fibrosis in obese mice with nonalcoholic steatohepatitis. Hepatology 45, 1366-1374.
Yamaguchi, K., Yang, L., McCall, S., Huang, J., Yu, X. X., Pandey, S. K., et al. (2008). Diacylglycerol acyltranferase 1 anti-sense oligonucleotides reduce hepatic fibrosis in mice with nonalcoholic steatohepatitis. Hepatology 47, 625-635.

Young, T., Finn, L., Peppard, P. E., SzkloCoxe, M., Austin, D., Nieto, F. J., et al. (2008). Sleep disordered breathing and mortality: eighteen-year followup of the Wisconsin sleep cohort. Sleep 31, 1071-1078.

Young, T., Palta, M., Dempsey, J., Skatrud, J., Weber, S., and Badr, S. (1993). The occurrence of sleep-disordered breathing among middle-aged adults. N. Engl. J. Med. 328, 1230-1235.

Young, T., Peppard, P. E., and Gottlieb, D. J. (2002). Epidemiology of obstructive sleep apnea: a population health perspective. Am. J. Respir. Crit. Care Med. 165, 1217-1239.

Zechner, R., Kienesberger, P. C., Haemmerle, G., Zimmermann, R., and Lass, A. (2009). Adipose triglyceride lipase and the lipolytic catabolism of cellular fat stores. J. Lipid Res. 50, 3-21.
Conflict of Interest Statement: Dr. Mirrakhimov declared his research was conducted in the absence of any commercial or financial relationships that could be construed as a potential conflict of interest. Dr. Polotsky is supported by the NIH grant R01 HL080105 and by ResMed Foundation grant 111481.

Received: 19 March 2012; accepted: 01 October 2012; published online: 17 October 2012.

Citation: Mirrakhimov AE and Polotsky VY (2012) Obstructive sleep apnea and non-alcoholic fatty liver disease: is the liver another target? Front. Neur. 3:149. doi: 10.3389/fneur.2012.00149

This article was submitted to Frontiers in Sleep and Chronobiology, a specialty of Frontiers in Neurology.

Copyright (C) 2012 Mirrakhimov and Polotsky. This is an open-access article distributed under the terms of the Creative Commons Attribution License, which permits use, distribution and reproduction in other forums, provided the original authors and source are credited and subject to any copyright notices concerning any third-party graphics etc. 